\title{
Understanding of Science Classrooms in Different Countries through the Analysis of Discourse Modes for Building 'Classroom Science Knowledge' (CSK)
}

\author{
Phil Seok Oh* $\cdot$ Todd Campbell' \\ Gyeongin National University of Education $\cdot{ }^{1}$ University of Massachusetts Dartmouth
}

\begin{abstract}
This study explored how teachers and students in different countries discursively interact to build 'Classroom Science Knowledge' (CSK) - the knowledge generated situatedly in the context of the science classroom. Data came from publicly released $8^{\text {th }}$ grade science classroom videos of five nations who participated in the Third TIMSS (Trend in International Mathematics and Science Study) video study. A total of ten video-recorded science lessons and their verbatim transcripts were selected and analyzed using a framework developed by the researchers of the study. It was revealed that a range of discourse modes were utilized and these modes were often sequentially connected to build CSK in the science classrooms. Although dominant discourse modes and their sequences varied among different lessons or different countries, the study identified three salient patterns of science classroom discourse: teacher-guided negotiation and the sequences of exploring - building on the shared and retrieving elaborating. These patterns were found to be different from the discursive features commonly witnessed in the community of professional scientists and interpreted as implying the existence of unique epistemic cultures shared in science classrooms of different countries. Further studies are suggested to reveal detailed characteristics of these epistemic cultures of science classrooms, as well as to confirm whether any cultural traits inherently shape the differences in science classroom discourse among different nations.
\end{abstract}

Key words: science classroom, discourse, classroom science knowledge, epistemic culture

\section{Introduction}

Helping students acquire core ideas or canonical knowledge of science is central to teaching science in schools (Michaels et al., 2008; National Research Council, 1996, 2011). Science education has been criticized, however, for an exclusive knowledge-orientation: the sole focus of school science education has been on transmitting scientific knowledge to students. But, this critique does not seem to target the knowledge education itself. It rather likely refers to the situation in which the scientific conceptual development is not pursued in connection with scientific practices and the nature of science even though the former is a product of the two latter. A more recent emphasis in science education has focused on scientific explanation and argumentation (Braaten \& Windschitl, 2011; Osborne \& Patterson, 2011), which helps maintain the inextricable link of scientific practices and the nature of science. But, these recent foci still hold the conceptual knowledge in science central. Therefore, studies are needed to analyze how knowledge is dealt with in the classroom so that we can better understand science classrooms and suggest constructive criticism and solutions based on these understandings.

There is agreement regarding the socioculturally situated nature of human learning. Many researchers from different fields of research, such as education, anthropology, and psychology, believe that learning takes place in a certain situation and the situation in turn affects the nature of learning (Barab \& Duffy,

\footnotetext{
*Corresponding author: Phil Seok Oh (philoh@ginue.ac.kr)

${ }^{* *}$ Received on 28 January 2013, Accepted on 3 May 2013

***This work was supported by the National Research Foundation of Korea Grant funded by the Korean Government (NRF-2011013-B00079).
} 
2000; Brown et al., 1989; Collins et al., 1989; Greeno, 1995; Greeno et al., 1998; Hennessy, 1993; Lave \& Wenger, 1991; Wells, 1999). Great emphasis is placed on learning environments in which people interact with one another and $\mathrm{co}^{-}$ construct context-specific knowledge under the influence of diverse sociocultural factors. In this view of learning, school science classrooms are sociocultural environments in which knowledge of science is constructed and developed through various types of interaction between the teacher and students. Of course, science knowledge addressed in the classroom is not totally new: it is versioned knowledge which is re-created from what scientists have generated into what has been deemed important and appropriate for students. But, the knowledge process in the science classroom is still considered creative in the sense that it contributes to the advancement of the state of knowledge in the classroom community (Scardamalia \& Bereiter, 2006). From this perspective, we would like to call the knowledge constructed situatedly in the context of the science classroom classroom science knowledge (CSK). As implied from the situativity viewpoint, CSK differs from the knowledge of professional scientists, and CSK developed in different classrooms would probably have different characteristics, depending on how lessons proceed and how the participants socially interact. In other words, a variety of CSK building practices would emerge when various science classrooms are investigated. Then, how do science teachers and students in different countries build CSK in their classrooms? The present study was conceived to answer this question by seeking to understand features of science classroom discourse in several different nations.

\section{Background}

\section{Vygotsky's Ideas}

Among many scholars inquiring into the nature of learning and human development, Vygotsky's ideas informed the theoretical underpinnings of this study. Vygotsky (1978, 1981) contends that social interactions on the place where people talk and work together - the social plane - are the primary process for individual development. Learning takes place with internalizing the knowledge which appears on the social plane into a learner's mind - the individual plane. In this process, it is crucial for the learners to interact with others who are more knowledgeable and capable than they are. This is because when people interact on the social plane, sophisticated knowledge and ways of solving complex problems are rehearsed by intellectually more mature participants and those knowledge and abilities are then appropriated in the learners' minds. Inspired by this notion, we view education as the social interactional process between an educational grown-up- more knowledgeable and capable participant and educational growing-up- less knowledgeable and capable one (Oh, 2005). In the science classroom, the teacher usually plays the role of an educational grown-up. But, it is possible for a student to assume the role of an educational grown-up when teaching his/her peers in a situation such as small group activities.

The Vygotsky's view of the relationship between language and learning provides an insight into how knowledge is built within the classroom community. Vygotsky (1987) does not agree with the traditional position that language serves as a vehicle for thought and emotion already existing in the mind. He argues, "Speech does not merely serve as the expression of developed thought. $\cdots$ [T]hought is $\cdots$ completed in word" (pp. 250-251). When people socially interact, various types of knowledge are developed by means of social speech which mediates interpersonal communication, and the social speech in turn transforms into inner speech directed to the participants themselves (Vygotsky, 1981, 1987; Wertsch, 1991). As a 
consequence of this transformation process, knowledge which once appeared between people is re-constructed in individual participants' minds.

When this principle is applied to science classroom instruction, the knowledge-building practice can be described as the recurring processes of construction, development, and internalization of CSK. That is, CSK is first constructed on the social plane of the science classroom by way of the teacher's, students', and/or their joint discursive acts. The CSK is then developed sophisticatedly while further addressed by the teacher and students, and it finally becomes internalized and re-constructed as personal knowledge (cf., Edwards \& Mercer, 1987; Leach \& Scott, 2003; Mortimer \& Scott, 2003). Throughout these processes, language serves as a cultural tool mediating interactions between the teacher and students, as well as a cognitive tool for shaping their knowledge and thinking (Mercer, 1995, 2000). Furthermore, it is expected that a variety of discursive modes are employed during the processes of constructing, developing, and internalizing the classroomsituated knowledge. Hence, analyses of science classroom discourse can contribute to our indepth understanding of science classroom education by revealing how the teacher and students use different sorts of discursive modes to collectively build CSK.

\section{Perspectives on Classroom Discourse}

Educational researchers have examined classroom discourse with interest in how the teacher and students interact to develop meaning in the classroom. Their studies commonly reported that classroom discourse was shaped in some dominant patterns of discourse including teacher monologues and IRE/IRF (Initiation-Reply-Evaluation/Follow up) exchanges (Cazden, 1988; Edwards \& Mercer, 1987; Lemke, 1990; Mehan, 1979). Especially, the IRE sequence has been a central theme of research on educational interaction and considered the unmarked case of classroom discourse. Researchers argue, however, that even if some discursive acts have similar exchange structures, their functions can be situated differently according to the contexts in which they are embedded. From a perspective of discourse analysis, context means the relationship of an utterance or discursive event to others which happen before and after the observed utterance or event. It also includes goals of activities, physical arrangements, materials used by participants, stances the participants take in their verbal moves, and their gestures as well (Gee, 1999; Mercer, 1995, 2008; Nassaji \& Wells, 2000; Ogborn et al., 1996; Roth, 2005; Wells, 1993). Even when the teacher is engaged in a monologic form of discourse, his/her talk is inherently social-cultural because the teacher's speech is still influenced by students to whom it is addressed and saturated with various contextual factors (Gee et al., 1992). Therefore, real meanings of a particular discourse vary with context, and the context itself is created along with the development of the discourse.

Previous studies have already recognized the contextual variations of classroom discourse. As an example, Edwards and Mercer (1987) indicated the important role of the IRE discourse in building what they call common knowledge in the classroom. According to them, the IRE pattern allows for the teacher and students to take on asymmetric roles in classroom interaction. That is, in the classroom, "some people help others to develop their understanding" and "knowledge is jointly constructed" by the participants with different levels of mastery (Mercer, 1995, p. 6). From this viewpoint, IRE is obviously the most prevalent pattern of discourse between the teacher and students as an educational grown-up and educational growing-ups, respectively. In fact, it is well-documented that the IRE exchange can perform many different pedagogical functions 
even though using IRE only, more often than not, results in teacher-dominant, closed classroom communication (Mortimer \& Machado, 2000; Nassaji \& Wells, 2000; Oh, 2005; Scott et al., 2006; Wells, 1993; Westgate \& Hughes, 1997).

Other studies focused on sequential features of classroom discourse rather than simply examining external structures of utterance exchanges. Ogborn et al. (1996), for instance, interpreted science teaching with four consecutive phases which comprise the process of explaining scientific concepts: creating difference, constructing entities, transforming knowledge, and putting meaning into matter. Mortimer and Scott (2003) also analyzed the meaning making process in the science classroom in terms of five linked aspects of science teaching interactions. In their framework, the aspect of communication approach includes the non-interactive but dialogic' dimension, which indicates that a teacher makes statements addressing students' or others' points of view while not calling for any turn-taking interaction. This dimension implies that the teacher's non-interactive monologue can even contribute to generating new meaning if it serves to revisit different ideas.

Based upon the perspectives discussed thus far, we assume that the teacher and students are not equal participants in classroom discourse and that the interactive patterns between the teacher and students are distinctive from those between young learners on the same level of knowledge and ability. In addition, in line with the research tradition emphasizing the contextual and sequential character of classroom discourse, we believe that in order to better understand science classrooms in terms of CSK building, it is necessary to examine teacherstudents interactions in consideration of contexts where different sorts of discursive modes are interlocked with one another to generate situated knowledge.

\section{Needs of the Study}

A number of studies on science classroom discourse and interaction have been conducted under the influence of the constructivist learning theory and qualitative research methodologies (e.g., Driver et al., 1994; Hogan et al., 2000; Kelly \& Crawford, 1997; Mercer, 1995, 2000; Mortimer \& Scott, 2003; Ogborn et al., 1996; Oh, 2005; Oliveira \& Sadler, 2008; Richmond \& Striley, 1996; Wells, 1999). Although these studies provided valuable information in identifying some important features of science classrooms, research literature that has attempted to understand science instruction by comparisons made across several countries is limited in number and investigative method. Most of the previous studies were completed looking specifically at one nation's classrooms, and when cross-national research was carried out sparsely, it was based mainly on quantitative survey methods. For instance, comparative studies were conducted between Asian and Western countries by using such classroom observation tools as the Constructivist Learning Environment Survey (CLES) and the Reformed Teaching Observation Protocol (RTOP) (Aldridge \& Fraser, 2000; Aldridge et al., 2000; Campbell et al., 2010). While these investigations made it possible to measure and contrast the degrees to which science classrooms in different nations conformed to reform-oriented principles of science teaching and learning, the studies were unable to disclose details of how science instruction actually took place in the participating nations because the investigations usually relied on numerical measures. It is thus needed to study science lessons in a more qualitative manner so as to understand more nuanced features of science classrooms in different countries.

Aldridge and Fraser (2000) pointed out that educational practices, beliefs and attitudes in a country can be understood more easily when they are exposed, made strange, and questioned 
by comparing those of other nations. Such comparative studies will reveal not only differences but also similarities in science lessons among different nations, and these findings will provide useful implications for better practices in science teaching and learning. Considering these, the current study aimed to understand science classrooms of five different nations by analyzing how the teacher and students socially and discursively interact to build CSK in their classroom. Research questions to be answered in this study are described as follows:

- What are the different kinds of discourse modes the teacher and students are engaged in, and how are these organized to build CSK in the science classroom?

- What are similarities and differences in science classroom discourse among different countries, and what do they imply about school science education?

\section{Methods}

\section{Data Selection}

Data for this study came from the Third TIMSS (Trend in International Mathematics and Science Study) video study. The TIMSS is an international assessment project of mathematics and science which is conducted every four years by the International Association for the Evaluation of Educational Achievement (IEA). In the Third TIMSS administrated in 1999, assessment of student achievement was completed, as well as a video study to look at classroom instruction. The video study was intended for the broad purpose of investigating and describing science instruction in $8^{\text {th }}$ grade classrooms across five nations: Australia, the Czech Republic, Japan, the Netherlands, and the United States. Out of these five nations, the first four were selected since their students outperformed U.S. students, and therefore one of the foci of the video study was on differences between the high- and low-achieving countries. In sum, 439 videos were collected as a random, nationally representative sample of science classrooms. From the 439 videos collected for the TIMSS video study, five videos from each of the five countries were released to the public with analysis results (Roth et al., 2006). While it is acknowledged that no individual lesson can capture the full range of characteristics of teaching, the released five videos were believed to reveal many of the typical features found in each country. Additionally, although changes in classroom instructions can and likely have occurred when comparing 1999 science instructions to those of today, this initial sample was seen as appropriate for the current study because of research suggesting the relatively static nature of classroom instructions overtime (e.g., Dow, 2006; Johnson, 2007; Tobin et al., 1991).

To select objects of the fine-grained discourse analysis of this study, a decision was made to rate the twenty-five videos with the RTOP (Piburn et al., 2000). The RTOP is an instrument for evaluating science instructions, using reform-oriented teaching behaviors as assessment criteria. Three trained raters independently rated each of the twenty-five videos and achieved an acceptable average measure intra-class correlation of .842 (F = 6.325, $d f=624$ ). Based on these RTOP ratings, the two highest rated science lessons from each country were chosen: Australia Lessons 2 and 5, the Czech Republic Lessons 2 and 3, Japan Lessons 4 and 5, the Netherlands Lessons 1 and 5, and the U. S. Lessons 1 and 4. Consequently, a total of ten video-recordings and their verbatim transcripts were analyzed to understand science classrooms from these nations. Information from the selected videos is presented in Table 1.

\section{Data Analysis}

The major task of this study was to investigate 


\section{Table 1}

Information of the Lessons Analyzed

\begin{tabular}{|c|c|c|c|}
\hline Lessons Al & zed & Lesson Topic & Major Activity \\
\hline \multirow{2}{*}{ Australia } & Lesson 2 & $\begin{array}{l}\text { chemical properties of metals and } \\
\text { non-metals }\end{array}$ & $\begin{array}{l}\text { teacher demonstration } \\
\text { student experiment }\end{array}$ \\
\hline & Lesson 5 & friction & $\begin{array}{l}\text { teacher demonstration } \\
\text { student experiment }\end{array}$ \\
\hline \multirow{2}{*}{ Czech Republic } & Lesson 2 & chemical compounds & teacher lecture \\
\hline & Lesson 3 & characteristics of matter & teacher demonstration \\
\hline \multirow{2}{*}{ Japan } & Lesson 4 & electricity & $\begin{array}{l}\text { teacher demonstration } \\
\text { student experiment }\end{array}$ \\
\hline & Lesson 5 & formation of clouds & $\begin{array}{l}\text { teacher demonstration } \\
\text { student experiment }\end{array}$ \\
\hline \multirow{2}{*}{ Netherlands } & Lesson 1 & suspension and emulsion & student experiment \\
\hline & Lesson 5 & becoming organ donors & student discussion \\
\hline \multirow{2}{*}{ United States } & Lesson 1 & weather map & student group activity \\
\hline & Lesson 4 & rocks & teacher lecture \\
\hline
\end{tabular}

science classroom discourse of five different countries in terms of CSK building. To fulfill this, we have developed a framework for analyzing classroom discourse on the basis of our reading of related books and articles (e.g., Cazden, 1988; Drvier, 1989; Driver et al., 1994; Edwards \& Mercer, 1987; Hogan et al., 2000; Hogan \& Pressley, 1997; Kelly \& Crawford, 1997; Kumpulainen \& Wray, 2002; Lemke, 1990; Mehan, 1979; Mercer, 1995, 2000; Mortimer \& Scott, 2003; Nassaji \& Wells, 2000; Nuthall, 1999; Ogborn et al., 1996; Oh, 2005; Oliveira \& Sadler, 2008; Richmond \& Striley, 1996; Roth, 2005; Wells, 1993, 1999). The reviewed literature had a wide range of variety in terms of the ways classroom discourse was addressed: some focused on external forms of utterances, while others emphasized functions of discourse and meanings generated through the discourse. These different approaches were considered together to shape a prototype of our own framework which included several different modes of classroom discourse. After an initial model of the framework was completed, we tested it out against examples of videos and transcribed classroom discourse and made several revisions. As a result, the complete version of the framework consists of eleven discursive modes which can be found in the processes of constructing, developing, and internalizing CSK in the science classroom. The discourse modes included in our framework are presented in Table 2.

\section{Table 2}

The Analysis Framework

Discourse Mode and Description

\section{Retrieving}

Retrieving is the discursive mode in which participants (i.e., teacher and students) verbalize wellestablished or pre-determined knowledge (e.g., textbook content, previously learned knowledge) with little change in the content and form. The retrieving mode is often found in talk where the participants 
are looking for one or more fixed answers to questions.

\section{Reformulating}

Reformulating is characterized by the transformation of knowledge into what is more accessible and understandable to participants. The reformulating mode of discourse may be accompanied with nonlinguistic resources such as models.

\section{Narrating}

Narrating is the discursive mode in which a participant tells a real or made-up story which includes such components as agents, sequences of events or actions, and their consequences.

\section{Exploring}

Exploring is the discursive mode in which participants' ideas are probed and accepted with little, if any, challenge or critique. The exploring mode also occurs in a natural or experimental environment where the teacher and students investigate new phenomena and describe some aspects of them.

\section{Elaborating}

Elaborating is the discursive mode in which participants' current knowledge and understanding are further developed by virtue of new information. In the classroom, elaborating discourse can be triggered by questions from students puzzled as well as concrete examples or problems presented by the teacher.

\section{Building on someone's experience}

Building on someone's experience is the discursive mode in which a participant constructs new meaning from his/her own or someone else's experience.

\section{Building on the shared}

Building on the shared is contrasted with the mode of building on someone's experience in that new knowledge is introduced on the basis of talk or experience shared between participants. The newly built knowledge often involves scientific ideas which are more general and abstract than the content of the shared talk or experience, and therefore the former provides an explanation of the latter.

\section{Debating}

Debating is the discursive mode in which participants with different ideas challenge and respond to each other usually through a series of questions and answers.

\section{Negotiating}

Negotiating is contrasted with debating in that participants who were engaged in challenge-response dialogues finally negotiate new meaning to resolve a conflict or solve a problem. Negotiating can occur with more ease when participants reach consensus on a current matter without explicit challengeresponse exchanges. Negotiating may be accomplished differently when it occurs among students and when the teacher is engaged in discourse. In the latter, the negotiating mode often proceeds with the teacher's leading and guidance, which results in adjusting the talk to move closer to more sophisticated knowledge and understanding 


\section{Scaffolding}

Scaffolding is characterized by evidence that a participant develops the ability to perform a task with independent competence thanks to guidance and support provided through discursive interactions with more knowledgeable and capable others.

\section{Metadiscourse}

Metadiscourse is the discursive mode which informs participants of what and how they are going to do in class (i.e., procedural metadiscourse). Metadiscourse also refers to the discursive mode which is intended to maintain a conducive classroom environment (i.e., managerial metadiscourse) and which provides evaluative and advisory comments for students (i.e., evaluative metadiscourse). Mostly, metadiscourse is constituted in the teacher's monologue, but at times it is completed in the exchange of student question and teacher answer.

The analysis framework was employed to examine the kinds of discursive modes the teacher and students were engaged in, as well as in what sequence they organized different modes to build CSK. The analysis was based on the theoretical perspectives of classroom discourse discussed earlier and implemented following methodological rules described next.

First, when analyzing the teacher's and students' discourse, we examined not only the external structure, but also the contexts in which they occurred. That is, in our analysis, the distinction between different discursive modes was determined through fully considering the discourse-embedding contexts. During the analysis process, it was also noted that each discursive mode did not always match with a specific pedagogical function, but instead the same discursive mode could serve different roles at different points of instruction. It was thus assumed that pedagogical roles of a certain discursive mode would be dependent on contextual factors as well.

Second, reflecting that discursive phenomena are spread over several utterances and that meanings develop in chains of utterances, not in one utterance (Draper \& Anderson, 1991; Kumpulainen \& Wray, 2002), our analysis did not focus on individual utterances, but rather used an episode as the unit of analysis. The episode is defined as a functional assemblage of discursive modes in which knowledge of a certain topic is built among participants through their discursive practices. An episode is divided into segments, which are distinguished from each other by a shift in such factors as a participant, an issue, and the way participants address the issue. That is, a new segment is recognized when a talk is initiated by a new participant, when a new issue under the same topic emerges, or when the way of talking (e.g., monologue, question-answer exchange) changes. Accordingly, one segment often corresponds to one type of discursive mode, and an episode includes multiple discursive modes sequentially connected to constitute a flow of interaction. In other words, our analysis was conducted to reveal what sorts of discursive modes were used and how they were organized in a topical episode to generate knowledge. After discursive modes and their sequences were identified for all episodes in a lesson, their meanings were interpreted qualitatively by considering various aspects of classroom discourse including pedagogical functions of discourse, roles of the teacher and students, and content of the knowledge built.

In the analysis process, the two authors of this study first worked independently to examine sample data. This was followed by comparisons of coding to determine consistencies and negotiate inconsistencies. The same procedure 
was applied repeatedly with increasing numbers of data sets. Consequently, after the first round of the analysis was completed, the interanalyzer consistency was computed as .97 in terms of the discursive modes identified. More extensive analyses and negotiations were then carried out to make necessary revisions and finalize the results.

\section{Findings}

\section{Common Features among Different Lessons}

Among the ten science lessons of the five TIMSS participating nations, seven began with reviewing previous lessons. As a result, the retrieving discourse mode, which is characterized by the practice of verbalizing well-established or pre-determined knowledge, appeared abundantly in the opening stage of the science lessons. The retrieving mode for the review was realized usually by repeating the exchange of teacher question and student answer. The same type of retrieving discourse occurred at the end of a lesson where the teacher and students recapitulated what they learned in the lesson. In all, three out of the ten science lessons had such a lesson-ending review section which involved a number of retrieving discourse. These discursive features related to the retrieving mode suggested that once CSK is generated, it is likely rehearsed repetitively by the teacher and students and that the retrieved knowledge often serves as a basis for developing new instruction.

The most frequently used discursive mode in the science classrooms was metadiscourse. This mode was employed mostly by the teacher whenever it seemed necessary for some pedagogical purposes. For example, at the beginning of a lesson when the teacher announced to the class an instructional topic and activities, he/she was usually engaged in the mode of metadiscourse. Also, when the teacher circulated around the classroom and conversed with small groups of students conducting experiments, the appearance of teacher metadiscourse increased greatly. The teacher's sole use of metadiscourse suggested that it was mainly the teacher who organized and developed classroom practices and discourse for students' learning. This is also consistent with our assumption that in the classroom the teacher and students play asymmetric roles as an educational grown-up and as educational growing-ups, respectively.

The teacher's metadiscourse was identified as three different types: managerial, procedural, and evaluative. The managerial metadiscourse refers to the talk which is intended to ensure that a lesson runs smoothly with few disruptive behaviors. The procedural metadiscourse informs students of what and how they are going to do to learn science in class, while the evaluative metadiscourse includes evaluative and advisory comments about the status of student learning. However, these three types of metadiscourse were not easily distinguishable in real talk, but rather often mixed in an utterance. Although most of the metadiscourse is situated in a long teacher monologue with only a few contributions from students, sometimes students began metadiscursive talk when they asked the teacher about experimental procedures, as an example.

Despite these common features, there were variations in how a lesson actually proceeded, and therefore more various types of discursive modes and their sequential connections were found in the science classrooms of the different countries studied. These findings are presented and discussed next for each of the five nations. In doing this, we considered that it was not desirable, in limited space of one research article, to address all the details of every discursive mode we found. Instead, we decided to focus mainly on what we identified as the most salient modes of discourse and their sequences that are found to be representative in each class or country. 


\section{Australia}

Both Australia Lessons 2 and 5 included science demonstrations and experiments and therefore showed high ratios of teacher metadiscourse and exploring discourse. The teacher-initiated metadiscourse was mostly either procedural or evaluative. That is, the Australian teachers often told students what they were supposed to do in experiments and gave evaluative comments on how well they were doing. The exploring discourse also appeared in two types. One occurred when the teacher and students described the demonstrated or experimented phenomena and collected data on these phenomena (i.e., exploring scientific phenomena). The other type of exploring discourse was initiated by the teacher to elicit student ideas about a topic (i.e., exploring student ideas). The following two excerpts are simple examples of these two different types of exploring discourse found in Australia Lesson 5 where students in groups were engaged in experiments about friction with such hands-on materials as a block and spring balance. In the first, the teacher gathered experimental data from students (exploring scientific phenomena), and in the second, he asked the students what they thought about the results (exploring student ideas).

41:16 T (teacher): How's the results going, guys?

41:18 S (student): We got 110 that one.

41:20 T: All right. And this one's less.

41:23 SN (new student): Yeah.

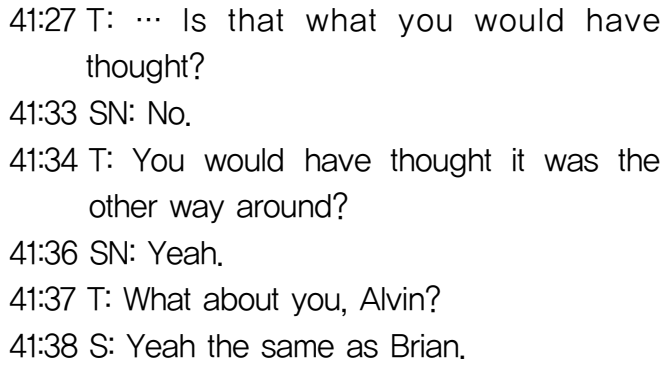

While there were similarities in lesson formats and discursive modes used, each Australian lesson manifested a salient discursive pattern. In Lesson 2, the sequential connection of exploring (scientific phenomena) - building (new knowledge) on the shared (exploration) was evident. For instance, in the excerpt below, the teacher and students are exploring discursively the scientific phenomena they observe when phosphorus is burnt and later put into water.

\section{4:34 T: And phosphorus burns with a?}

14:37 SN: White smoke?

14:38 T: With a white smoke. $\cdots$ Now what will happen is the white smoke, you got a white powder before?

14:51 SS (students): Yeah. Yes.

14:52 T: The white smoke will now dissolve in the water. What happens when the white smoke,

14:58 SN: It goes red.

This exploring discourse was followed by the building-on-the-shared discourse presented in the next excerpt, where the teacher introduced scientific language to interpret the explored phenomena. In other words, scientific knowledge was built using the exploration shared between the teacher and students as a foundation. It should be noted that the newly built knowledge includes a more general scientific idea and renders the explored phenomena explained.

15:13 T: The non-metals burn in air to form a white powder. That white powder dissolves in water to form a solu-, a substance which turns that indicator red. That indicates that a substance is an acid. $\cdots$ For some reason they call that white powder, there is an, it's an oxide. It's called an acidic oxide. Why is it called an acidic oxide?

15:47 SS: (inaudible) acid.

15:48 T: Because it dissolves in water to form an? 15:50 SS: Acid.

15:51 T: Acid. Right. 
Sometimes the "exploring - building on the shared' sequence was complemented by elaborating discourse, and the exploring (scientific phenomena) - building (new knowledge) on the shared (exploration) elaborating (the newly built knowledge) pattern appeared. The first segment below, as an instance of the building-on-the-shared mode, shows that the teacher generalizes the results of previous explorations about non-metals to include all other non-metallic chemical elements. In the second segment, the teacher and students switch their discourse to the elaborating mode so that they can expand the knowledge about non-metals to a wider, everyday life context.

17:49 T: How can you tell the difference between, $\cdots$ if those two non-metals burn in there to form an oxide which dissolves to form an acid, what would you assume? That other non-metals will do?

18:06 SS: The same.

18:07 T: The same thing.

18:07 T: For example. Carbon's a non-metal. It burns in there to form?

18:14 SN: Carbon oxide.

18:15 T: Carbon oxide. Carbon oxide dissolves in water to form? An acid. Do we ever use that acid? How many of you have seen carbonic acid? '.. You drink it every time you have a mouthful of soft drink. '. How do you make any kind of soft drink? Out of? ...

18:39 SS: Carbonated water.

18:41 T: $\cdots$ what do you do to carbonate water? $\cdots$ You put into it?

18:47 SN: (inaudible)

18:48 T: Carbon oxide. Carbon dioxide.

When we examined all the episodes in Australia Lesson 2, the building-on-the-shared mode was found often in the central of classroom discourse as shown in the two examples provided. This meant that in the Australian science lesson, CSK was built on the basis of experiences shared between the teacher and students. In this knowledge-building practice, it was the teacher who led students in exploring scientific phenomena and presented scientific knowledge based on the exploration.

It was worth noting that Australia Lesson 5 included several cases of negotiating discourse in which the teacher challenged students discursively to change their initial idea and reach an understanding of scientific knowledge. For example, in the introductory phase of Lesson 5 , the teacher elicited from students the answer that the natural state of things was 'stop'. Now the teacher poses several thought-provoking questions, such as "Everything [does] that?" and "What if you fire a rocket?", to lead a conversation, which drives the students toward a scientifically more valid conclusion, "Except for that [a rocket in space]".

05:04 T: Everything [does] that?

05:05 SN: Yes. $\cdots$

05:08 T: Even a trolley?

05:09 SN: Eventually.

05:09 T: Eventually. What if you throw a ball?

05:14 SS: Yes. $\cdots$

05:17 T: What if you fire a rocket?

05:19 SS: Yes.

05:20 T: Into space?

05:21 SN: Yeah.

05:27 T: Once it gets away from earth, does it stop?

05:30 SN: Yes, oh, no.

05:31 SN: No. $\cdots$

05:34 SN: Not until it hits something. '- Like a planet.

05:38 SN: Asteroid.

(The conversation continues till the teacher summarizes the issue.)

06:12 T: From what we've talked about $\cdots$ what would your conclusion be? Do things tend to come to rest? Keep moving? Or something else that you 
might like to suggest. $\cdots$

06:27 SN: They tend to stop?

06:28 T: They tend to stop like rockets that are going to space.

06:33 S: Well, except for that.

The excerpt above illustrates how negotiating discourse can occur between the teacher and students who are on different levels of science mastery. That is, in the science classroom, the teacher often leads a dialogue with questions puzzling students and guides the students in such ways that they can negotiate more sophisticated knowledge or expressions. As another example of negotiating discourse between the teacher and students, a conversation occurred soon after the teacher explored students' idea that if an object keeps moving, there is force acting on it. Instead of correcting the misconception immediately, the teacher suggested a challenging situation that "rockets .. keep moving after the engines are turned off" and presented several clues. As a result, the students eventually became dissatisfied with their original idea and came up with the right conclusion that a rocket will keep moving if there is no force to stop it.

The negotiating discourse found in the Australian science lesson is distinguished from genuine negotiating discourse occurring in everyday life situations in which people with conflicting ideas settle the difference by reciprocal concessions or modifications to gain mutual advantage. In contrast, the sort of negotiation identified in the Australian lesson can be called teacher-guided negotiation in the sense that it is intended pedagogically by the teacher to help students acquire sophisticated scientific understanding. In other words, the teacher-guided negotiating discourse served to develop CSK as aligned with canonical knowledge of science by assisting students in adjusting their knowledge to fit with scientific understanding.

In Australia Lesson 5, however, the teacher's attempt to negotiate scientific understanding with students was not always successful. In the excerpt below, the teacher was trying to change the misconception that force is needed to keep something moving by asking questions and conducting simple demonstrations. But, as implied by his utterance, "We' ll talk more about that at the end", the teacher' s attempt failed after all.

15:03 T: Would, Diane, would you agree that after, after l'd given that a force, a shove like that, and I'm not touching it anymore, would you agree that I' $\mathrm{m}$ not applying any more force to it? $\cdots$

15:23 SN: [You applied force before] and like it loses the force gradually, slowly as it's sliding across the table as it gets slower.

15:29 T: Loses the force.

15:30 S: Yeah, like, loses energy like,

15:32 T: Well, energy is different from force, isn't it? $\cdots$ Okay, anyway, coming back to this argument. After l've set it in motion, let's say there was no air resistance and no friction. $\cdots$ If it keeps moving, a number of you said it needs a force to be acting to keep it moving. What force is then acting on it to keep it in motion? ... What keeps it moving then? $\cdots$

17:33 SN: Your hand did.

17:33 T: No, l've, I've taken my hand away after that initial contact like that. It's no longer there. Gabriel?

17:40 SN: Tension? That stored energy.

17:44 T: Stored energy. Is, is that a force?

17:46 SN: Yes.

17:47 T: No. We're talking about two, like apples and oranges, all right? Can't talk about them as being the same. ' ' So force and energy, different ideas. Okay. All right. We' II talk more about that at the end, okay?

If the teacher and students had negotiated 
scientifically accepted understanding at the end of this conversation, it would have produced the discursive sequence of exploring (student ideas) - debating (between different ideas) negotiating (scientific ideas), which we believe is one of the ideal patterns for knowledge-building in science classrooms. Unfortunately, however, the discourse remained in the debating mode rather than developing into the negotiating mode.

\section{Czech Republic}

As in most other classes, Czech science lessons began with reviewing previous lessons. However, a few distinctive connections of different discursive modes were found in the opening phase of the Czech lessons. First, it was observed in Czech Lesson 2 that the teacher and students were engaged in the sequence of procedural metadiscourse - retrieving evaluative metadiscourse. That is, the teacher initiated a discursive episode with metadiscourse to assign tasks to students in the class, then engaged some students in answering his questions by recalling their knowledge, and finally assessed the students' performance with another type of metadiscourse. An example of this discursive sequence is presented below. In the first segment, which was classified as procedural metadiscourse, the teacher separated the class into two groups to give different tasks and started his talk with four selected students.

07:30 T: Now, everybody in class, please open your books. Group A will look up page 114. There is a table, number nine. Please fill out the table with your pencil. Okay? Group B of the class turns to page 118. It's the assignment number five and there is a table. Fill it out with your pencil as well. And those of you up here, we will continue. I will ask you some questions and you will answer them. Okay?
The teacher's interaction with the chosen students proceeded for about three and half minutes right after his utterance above. The following excerpt shows a piece of this interaction, where the teacher sought a single correct answer for each quiz question, and a student kept providing an answer by successfully retrieving what he already knew.

08:37 T: Can you name some fertilizers?

08:42 S: Mineral fertilizers.

08:43 T: Mineral fertilizers. Can you think of other fertilizers?

08:46 S: Organic fertilizers.

08:47 T: Organic fertilizers. Can you name some organic fertilizers?

08:49 S: Those can be found on ranches and farms.

08:51 T: And they are?

08:53 S: Manure, sewage.

08:56 T: Sewage.

08:58 S: And wastewater.

09:01 T: The wastewater.

Completing this retrieving discourse with the four selected students, the teacher provided evaluative metadiscourse as follows.

11:51 T: Now everyone, grab a piece of chalk because you will write your grade. This student gets a B grade, you get an A, you get a B and you get an $A$. Those are your grades.

The 'teacher metadiscourse - students retrieving - teacher metadiscourse' sequence found in Czech Lesson 2 has a similar structure to the IRE pattern even though the former is based on larger context. It can therefore be thought that this discursive sequence is representative of the well-structured, teacherled classroom interaction of the Czech science lesson.

The well-structured nature of Czech science classrooms was manifested by other discursive 
patterns revealed in both Czech Lessons 2 and 3: the sequential connection of retrieving (knowledge) - elaborating (the retrieved knowledge) or retrieving (knowledge) - exploring (new phenomena relevant to the retrieved knowledge). This meant that the class first shared scientific knowledge and then enhanced the knowledge by use of relevant examples (elaborating) or new investigations (exploring). Particularly, the retrieving - exploring sequence appeared more often at the beginning of Lesson 3 than Lesson 2. The following two excerpts present an example of this discursive connection found in Czech Lesson 3. In the first, the teacher told students to recall what they previously learned about mixtures, and in the second, he provided the students with an opportunity to look closely into a new phenomenon related to the recalled knowledge.

07:49 T: Another method of mixture separation, is crystallization.

07:53 SN: Crystallization. ...

08:17 T: ... l'd like to ask you first? Is naphthalene soluble? Do you remember? In water?

08:32 SS: No.

08:34 T: In what is naphthalene soluble?

08:35 SS: In organic solvents.

08:37 T: In organic solvents. Correct.

08:37 T: So now $\cdots$ I have the naphthalene in the test tube, and let's add the organic solvent. As you can see, the naphthalene is really dissolving, isn't it? ... So now … । drop a little bit of the dissolved naphthalene, l' ll put a drop in the Petri dish. $\cdots$ So now you can see it. It's appearing in the reflection and everybody can see it. What do you see, slowly?

10:40 SS: Crystallization.

10:43 T: Yes. You can start seeing little crystals.
It is evident that in the retrieving - exploring sequence above, the exploring discourse fulfills the same pedagogical function as elaborating discourse because it provides a scientific phenomenon which was a concrete application of scientific concepts, in this case, solubility and crystallization. Thus, depending on context, exploring discourse can serve to strengthen student understanding of scientific ideas. Perhaps for this reason, the use of the retrieving - exploring sequence was not limited to the beginning stage of the Czech lessons. In fact, the same discursive sequence was employed in the middle of Lesson 2 as well. As an example, the following episode consists of three interlocked discursive modes: retrieving (knowledge) exploring (new phenomena relevant to the retrieved knowledge) - elaborating (the retrieved knowledge). That is, the teacher presented scientific knowledge about potassium permanganate in the first segment, offered a chance for students to investigate a new phenomenon related to the substance in the second, and provided a real life example in the third.

32:30 T: The next one $\cdots$ It's $\mathrm{KMnO}_{4}$. What does that mean?

32:39 SN: Potassium manganate.

32:40 T: Potassium manganate. $\cdots$ It is given in the table. Potassium permanganate. $\cdots$ What is it used for? As a disinfectant and oxidizing agent. Write down, disinfectant and oxidizing agent. Okay.

34:03 T: I would like to return to the potassium permanganate. I brought one for you to see. $\cdots$ I'm going to demonstrate, yes it dissolves into a purple liquid. Let's take a look here, at this Petri dish and I'm going to place several crystals and pour in some water.

34:40 SN: It is very interesting.

34:43 T: Very good. What kind liquid is it? You can all see that it's, 
34:50 SN: Pink color.

34:51 T: The pink liquid. $\cdots$

34:56 T: In the civilian world, for example, kids are taught to use potassium permanganate, for disinfecting masks and so on. $\cdots$

As shown thus far, the Czech science lessons are characterized by the extensive use of the retrieving discourse mode with other modes in support of it. Further, most of the retrieving discourse was completed when the teacher asked students to recall scientific knowledge, students successfully provided it, and the teacher presented further information, just as in the IRE pattern. This feature is interpreted as implying that constructing and developing the basic knowledge of science as CSK is the most important concern in the Czech science lessons. In the TIMSS video data analyzed in this study, however, evidence were hardly found for how the Czech students had first come to know the knowledge they retrieved in the classrooms.

\section{Japan}

Japan Lessons 4 and 5 included teacher demonstrations and student experiments, and therefore a number of teacher metadiscourse and exploring discourse were identified. The metadiscourse was focused on clarifying experimental procedures, setting up experimental equipment, trouble-shooting during experimentation, and commenting on student performance. The exploring discourse occurred mainly when the teacher and students spoke about what they observed in the experiments, as well as when the teacher collected data from student groups. Hence, in many cases of teacher-student conversations, metadiscourse and exploring discourse were mingled and difficult to separate from each other.

The Japanese lessons were differentiated from those of other nations in that teachers explored student ideas extensively before a demonstration or experiment was conducted. The first experiment of Lesson 4 was about materials generating heat when electric current was applied. For this experiment, the teacher prepared four different materials to be tested, and before starting the experiment, she encouraged students to present their predictions. The following excerpt is a part of this exploring discourse.

02:34 T: Then I will ask you. Okay? Then who thinks that the enamel wire will generate heat?

02:41 T: One, two, three, $\cdots 221,22,23$. Okay. Twenty-three.

02:52 T: Miso soup. Miso soup with read bean paste.

02:53 SN: Yes. $\cdots$

02:56 T: One, two, three, four, five, six, seven. Okay.

03:00 SN: That has a lot of sodium.

03:02 T: Then the lead of a mechanical pencil.

03:04 SN: This is serious.

03:05 T: One, two, three, ... 10, 11, 12. Okay.

Similar to Lesson 4, in the beginning of Lesson 5 , the teacher engaged students in exploring discourse in which the students expressed their ideas about how clouds form. Based on our observation that Japanese students actively participated in practical work and talking about what was happening, the exploring discourse in the Japanese lessons seemed to be successful in motivating students and drawing their attention. However, the exploring discourse preceding the experiment in Japan Lesson 4 was limited to collecting student predictions of experimental results and did not reach the level of probing the students' theories behind the predictions. Likewise, the teacher and students in Lesson 5 did not develop their conversation further to discuss the scientific mechanism of cloud formation beyond simply mentioning where clouds form (e.g., sea, sky) or what is precursory 
to the cloud formation.

The Japanese science lessons were found similar to Australian ones in the sense that their discursive practices were characterized by the building-on-the-shared mode coming after the exploring mode. The following excerpt from Japan Lesson 4 presents an example of building-on-the-shared discourse, where the teacher draws a conclusion from a stock of data gathered in student experiments.

46:21 T: Then, let's take a look. I stuck all of them together. Then the result of your measurement became like this. ... When the voltage and the current are both zero, there is neither temperature nor heat energy. Here. Origin, okay? Then I will draw a line so that it is close to all the dots.

47:08 SN: Oh! Amazing! They are exactly on the line!

47:10 T: Yes, some are exactly on the line. $\cdots$ What can we say from this?

47:18 SN: This is amazing.

47:23 T: Voltage times current equals ... what kind of relationship is there in relation to temperature increase and heat energy?

47:40 SN: Proportion. (Several students respond with the same answer.)

47:49 T: ... It has a proportional relationship, right? $\cdots$ We found that heat energy is proportional to the product of voltage and current.

After this conversation, the teacher probed student ideas about the relationship between resistance and heat generation, and then introduced additional scientific knowledge by generalizing a common idea among student groups. The building-on-the-shared discourse was also one of the representative modes in Japan Lesson 5. That is, at the end of the lesson, the teacher asked students to present what they observed in their experiments using a syringe and air pump to make clouds (exploring), then summarized the results on the blackboard with the students writing them down in their notebooks (retrieving), and finally provided scientific ideas about cloud formation on the basis of the results presented and shared by the students (building on the shared).

As already noted, the building-on-the-shared mode was central to the development of CSK in Australian science classrooms where the main class activities were teacher demonstrations and student experiments as well. Therefore, when we consider the common characteristic of Australian and Japanese science lessons, it can be proposed that the discursive sequence of exploring (scientific phenomena) - building (new knowledge) on the shared (exploration) is typical to guided inquiry and the guided construction of CSK in which the teacher plays the key role in providing guidance and support for students to investigate scientific phenomena and learn scientific knowledge from the investigation.

In addition to the teacher' s extensive use of exploring discourse and the sequence of exploring - building on the shared modes, Japan Lesson 5 revealed a couple of reformulating discourse modes in which the teacher made use of analogical models to explain the scientific process of cloud formation. At first the teacher used a vacuum pump and later a bicycle pump to illustrate air compression and expansion which are necessary processes in the formation of clouds. The excerpt below shows the teacher's reformulating discourse which occurred at the beginning of the lesson.

03:45 T: This is a tool to take out the air inside. This is a vacuum pump. ' . And you let air out, so what happens to the air inside?

04:19 SN: Vacuum.

04:20 T: Yes, if you say it in technical words, it forms a vacuum. It gets thinner. A state like this happens in nature too. Think about the sky. The upper air. What is the air like far up in the sky? 
04:35 SN: Thin.

04:36 T: Thin, right? It's thin. Compared to the air around here, the air in the sky is of course thinner. We produce that state in here. $\cdots$ The air in this glass container becomes thinner. ... but there is a balloon in here. This balloon is a little bit inflated. $\cdots$ When the air around becomes thinner, what happens to this balloon? $\cdots$

06:13 SS: It is inflating.

06:15 T: Can you see that it is inflating? Can you see it inflated more than before? $\cdots$ What does this mean? The air around this gets thinner means, uh, it gets thinner and this balloon gets inflated. I am going to turn this off and let the air come in. It shrinks, right? This was conducted in nature too, rather it is happening. In short, the air around here goes up. Then, as you saw with this balloon, it grows. In short, the air expands in volume. Can you understand the meaning of "expand in volume" mean? $\cdots$

07:38 SN: Grow.

07:39 T: Yes, simply said, it grows. It is in a state in which volume increases, when it goes up. ... I' $\mathrm{m}$ sure that you saw it from this, what will happen when it expands.

This segment provided evidence that one of the teacher's concerns in the science classroom was to make scientific knowledge more accessible to students. In this case, the teacher took advantage of everyday equipment (i.e., pumps) easily found in students' lives to explicate the abstract concept of adiabatic processes involved in the cloud formation. Alternatively speaking, in the Japanese science lesson, CSK at times came in a translated form of expert knowledge of scientists.

\section{Netherlands}

The two Dutch lessons were different from each other in terms of class types: Lesson 1 involved student group experiments with solutions and mixed substances while the main activity in Lesson 5 was teacher-students and student-student discussion about organ donations. Consequently, a number of metadiscourse for managing science experiments as well as exploring discourse related to the experimental phenomena were found in Lesson 1. Although exploring discourse was also frequently used in Lesson 5, it was mostly intended for probing students' opinions about several issues around organ donations rather than gathering information from experiments.

As in Australia Lesson 5, it was observed in Dutch Lesson 1 that guided negotiation occurred between the teacher and students. One of the objectives of the science experiments in this lesson was for students to make different mixed substances and identify what kinds of mixtures they were. In the following dialogue, for example, the teacher and students were in the exploring mode of discourse to talk about the observed properties of the mixture they had just made.

27:08 SN: Pink below ... pinkish (inaudible)

27:16 SS: (inaudible) We have a milkshake.

27:21 T: Did you make a solution? ...

27:25 S: Un ... I did here.

27:27 SN: No.

27:28 T: Why,

27:29 SN: No, because it's not clear.

27:30 T: It's not clear, is it? So then it's not a solution. $\cdots$

27:32 S: It is going to sink, just like that one. That one was okay as well.

After having finished this exploration, the teacher moved on to ask the students a question about the type of the mixture. Although a student answered wrong at 27:39, the teacher did not correct it immediately but tried to probe the student' s idea further by asking, "Why?" As a result, the student came up with a description 
of the mixed substance at 27:42, and, reflecting this answer, the teacher posed a challenging question at 27:44.

27:34 T: It's not a solution. So then what is it? A suspension or an emulsion?

27:39 S: Un ... a suspension?

27:41 T: Why?

27:42 S: Because it doesn't dissolve into each other.

27:44 T: Yes, but then it could still be an emulsion, couldn't it?

This excerpt was considered a beginning of teacher-guided negotiating discourse because it was obvious that the teacher intended to lead the students discursively to reach an accurate identification of the mixture in question. In this case, the teacher fulfilled his pedagogical intention by engaging the students in retrieving discourse as below.

27:44 T: What was the difference again between a suspension and an emulsion?

27:52 SN: With one it's a solid substance, and with the other it's a liquid (inaudible).

27:56 T: Exactly. Look for yourself, it's even written on the blackboard.

In this excerpt, the teacher asked the student to recall the definitions of suspension and emulsion, which had already been covered in the class, and notably, the knowledge retrieved by the student was used as a basis for negotiating discourse that happened right after this conversation. That is, by virtue of the teacher's challenging question and the retrieved knowledge, the students correctly identified the type of the mixture as shown in the following excerpt.

27:59 T: And so, what have you got? ...

28:06 S: $\cdots$ We made an emulsion.

28:07 T: Yes, you've made an emulsion. Therefore, a real milkshake, that's?

\section{8:13 S: Emulsion.}

This episode supports our conceptualization of teacher-guided negotiation: in the science classroom, the teacher leads students in discourse to adjust their current understanding, which is often incorrect or incomplete, to fit with canonical knowledge of science. Further, the episode reveals that retrieving discourse is not always to blame, for in this case, the retrieving discourse played a mediating role between exploring and negotiating discourse and contributed to negotiating knowledge in a new situation different from the one in which the knowledge was addressed originally. Therefore, it can be suggested that the usefulness of a certain discourse mode depends on how it serves to meet a goal of instruction, including the goal of constructing more valid and more reliable scientific knowledge.

In addition to the teacher-guided negotiation, the Dutch lesson was distinguished by elaborating discourse initiated by students. In science classrooms, elaborating discourse may be triggered by a student who is puzzled and as such wants to gain new information to resolve his/her curiosity, and this was the case in Dutch Lesson 5. In the following excerpt, as an example, students asked a series of questions about organ donations and received elaborated answers from the teacher.

30:24 SN: But miss, can you still become a donor when you have been sick or unhealthy yourself?

30:32 T: Yes. Because that doesn't necessarily mean that all of your organs are sick as well. That's possible.

30:40 S: Yes, but if you've (inaudible) have smoked? ...

30:46 T: If you have smoked. Then your lungs will not be of much use, but your liver might be working fine. Or your skin.

(The student and teacher exchange another question and answer before a new student 
poses a question.)

31:15 SN: Suppose later you do want to give something to your family, then isn't it a bad thing that you have said no on that sheet? $\cdots$

31:23 T: Whose choice is that? $\cdots$

31:30 S: Well, of yourself.

31:32 T: Yes, whose body is it? Whose body is it about?

31:37 S: Well, your own.

31:40 T: Yes, and the moment they ask you, "What would you choose?" then there is no such thing like one choice being right and the other being wrong. $\cdots$

This conversation is worthy of attention, especially because the students do not simply ask questions but rather express their opinions in some imagined situations of organ donations. This implies that the students have a certain level of understanding of the topic, as well as an eagerness to strengthen it with new information. Sometimes such student willingness to learn offers a chance for scaffolding discourse, which is characterized by students' independent competence of talking and using scientific knowledge. A unique example of scaffolding discourse was observed in Dutch Lesson 1. During the experiment with several chemical substances, a student posed a query about the function of a detergent, and the teacher provided elaboration.

29:08 SN: Miss, the function of (inaudible).

29:11 T: No, the function of the dish-,

29:14 SN: Here, this is the oil.

29:16 T: We call the whole emulsion, and the dishwashing detergent is what we call the emulsifier. $\cdots$ So the soap is the emulsifier and that' $s$ the substance that prevents the two liquids from separating. So that's the function of the soap. Making sure that the two liquids don't separate. Because here they separated, didn't they?
29:49 S: Yes.

29:49 T: Here it's not a mixture anymore. So the soap makes that those two liquids that don't dissolve into each other, that they do not separate.

Remarkably, the dialogue did not end this way. In fact, about a minute later the teacher came back to the same student and listened to what he described about his observation. This revisitation provided the student an opportunity to explain the experimental phenomenon using a scientific concept independently with no help from the teacher. This was why the segment below was coded as the scaffolding discourse mode in this study.

30:44 T: Now, what do you see? $\cdots$

30:46 SN: The emulsifier (inaudible) causes the substances not to separate.

30:49 T: Correct. Very well.

In the Dutch science lesson, there were more pieces of evidence that revealed students being actively engaged in their own learning. For example, exploring and debating discourse between students were observed in Lesson 5 . The between-students exploration and debate usually occurred when the students discussed their decisions about which organs they would donate and what kinds of advantages and disadvantages they could anticipate from the organ donation. Another evidence of Dutch students' active participation was the negotiating discourse in which a student contributed significantly to resolving a matter for the lesson. In the following excerpt, a student found a problem in the list of donor organs, which called for negotiation within the class. While the teacher vainly attempted to fix it by excluding 'lungs' from the list, a student provided new information as counterevidence to the teacher' $\mathrm{s}$ utterance, so that the teacher could reach an agreement. 
18:15 SN: Which were those six organs again? I' $m$ seeing only five.

18:17 T: Lungs were also part of it. No, we haven't gotten to that yet. We don't need to yet. $\cdots$

18:33 SN: Madam, lungs are possible. Somebody from my old class his mother had to be on an oxygen tank all the time,

18:38 T: And she got a lung transplant?

18:39 S: she got a lung transplant. Then she didn't have to do that anymore.

18:40 T: Yes? Lung transplant, let's add that, then.

Thus, the Dutch science classroom, in comparison to other classes examined, showed relatively more examples of students' contribution to CSK building. As presented, the learners' contributions were realized through various discursive modes including elaborating, scaffolding, and negotiating.

\section{United States}

The major activity of U.S. Lesson 1 was student group work for composing weather maps and, just as other classes including practical work of students, metadiscourse by the teacher was dominant. Interestingly, however, retrieving discourse also appeared in abundance during the weather map activity. In reality, the metadiscourse and retrieving discourse either occurred in turn or were mingled in the teacher's talk. This was because the teacher had to continually help students recall what they needed to know to create a weather map, including what weather symbols stand for and how particular weather conditions should be represented on weather maps. This kind of information was not contentoriented, per se, but related to the procedure of weather mapping. Therefore, the knowledge retrieved through discourse was necessary for students to carry out the science activity properly. Exploring discourse also took place between students while they were trying to find specific cities on weather maps, and negotiating discourse was found as well when the teacher and students reached consensus about the location of a particular city.

U.S. Lesson 4 proceeded in a way of teacher lecturing, but it included various instructional materials, such as landscape photos and rock samples. Additionally, a chart of the lesson content was projected on the screen, so that all students in the class could see. Although all these materials were used throughout the lesson, the teacher particularly relied on the content chart to retrieve scientific information of rocks and their formations. The content chart was also used when the teacher asked students to locate information related to their observations of rock samples.

In spite of the different types of classroom activities, both U.S. science lessons included the retrieving (scientific knowledge) - elaborating (the retrieved knowledge) sequence, which was also observed in the lessons of other countries including the Czech Republic. This pattern was especially dominant in Lesson 4, where it was usually the teacher who played major roles in retrieving scientific knowledge and elaborating it. The teacher's elaborating discourse was often accompanied by presenting real rock samples which students were allowed to see and touch. In the following two excerpts, for instance, the teacher first retrieved scientific information from the content chart and then helped students elaborate the information by showing a real rock pegmatite.

25:05 T: If you're wondering how I'm naming these rocks, it's all on the chart. $\cdots$ Now, notice on your chart it says color: light. So these rocks over here are all light in color. '. So since they' re light in color, I know and you should know that it could be granite or rhyolite, or even a rock called the pegmatite. Now, look over here where it says grain size. That's a 
way of describing the crystal size. $\cdots$ Which of these words, which of these correspond to something that has a fine grain or tiny crystals? Look at the measurements.

26:29 SN: Less than,

26:30 T: Okay. Less than one millimeter or less than a tenth of a centimeter, light colored. That rock is rhyolite. But if it has bigger crystals, let's say a tenth or one millimeter to a centimeter big,

26:50 SN: It's granite.

26:51 T: That's right. Then it's granite. $\cdots$ Now, if the rock took a real long time to cool, if it's one centimeter or 10 millimeters or larger, then it's called pegmatite.

27:14 T: $\cdots$ Here's the pegmatite. Look how big those crystals are. There's one crystal right here. It's feldspar. All right? So this one took a real long time to cool. The crystals are really big. We say it has a very big grain size.

The teacher in U.S. Lesson 4 also took advantage of real life examples, histories, and movies to elaborate his explanations of the properties of rocks. As an example, the following conversation occurred after the teacher and students studied about ballistic glass. Evidently, the teacher was successful in drawing student attention to his elaboration of the glassy texture of a rock by using an example of cavemen shaving.

31:24 T: If you ever wondered, how did the cavemen shave..

31:31 SN: With rocks.

31:32 SN: With basaltic $\cdots$

31:34 T: This. If you hit it the right way, it flakes off, and you get something as sharp as a razor blade, even sharper than a razor blade, and that's how they shaved. $\cdots$ another thing is, this is, one of the items that Indians used as arrowheads and knives.
The retrieving - elaborating pattern was, at times, preceded by exploring discourse in which students willingly expressed their ideas in responding to the teacher's questions. The excerpt below is an example of the exploring discourse followed by retrieving and elaborating discourse, where the teacher showed a photo of his own and told students to guess what kind of a landscape he was on.

07:20 T: All right. Any idea where I am? ... Well, I don't mean the exact, I can tell you the exact location, but the type of landscape I' $m$ on.

07:39 SN: Ice.

07:40 T: No. It's not ice, Samuel. ‥ Sonia?

07:46 SN: Is it a mountain?

07:47 T: It's a kind of mountain.

07:49 S: A cliff?

07:50 T: I don't know if you can call it a cliff.

07:53 SN: It's a rock.

07:55 T: I' m standing on rock.

08:16 SN: Maybe you're standing on a rock, and the sediments in the middle are eroding.

08:22 T: No. That's not how this hole got here. All right. Rudy?

08:31 SN: A river went in the (inaudible), and it dried out.

08:35 T: Let me tell you where it was, all right? This is in an island,

08:42 SS: Hawaii.

08:45 T: Does that help? The island of Hawaii. ... But there's something about the Hawaiian islands. ' . What is that? What was that? Jeffrey?

09:06 SN: They' re all volcanoes.

09:07 SN: They' re volcanoes.

09:08 T: That's right.

09:09 SN: You' re on a volcano. $\cdots$

09:12 T: So I' $m$ standing on a vol-, near the top of a volcano. $\cdots$

This dialogue ran for about four minutes before the teacher began his retrieving discourse 
about igneous rocks and elaborating discourse on the difference between lava and magma. Considering the amount of time devoted to the dialogue, it was certain that the exploring discourse served to motivate the students to learn the subject. However, there was little evidence that the teacher used the students' ideas as a foundation to build his presentation of scientific knowledge, because most of the time he relied on the content chart projected on the screen as a source for retrieving knowledge.

On some occasions in U.S. science lessons, reformulating discourse replaced elaborating discourse or complemented the retrieving elaborating sequence, so that the retrieving (scientific knowledge) - reformulating (the retrieved knowledge) or retrieving (scientific knowledge) - reformulating (the retrieved knowledge) - elaborating (the retrieved knowledge) pattern appeared. As an example of the teacher's reformulating discourse in replacement of elaborating discourse (i.e., retrieving - reformulating), the teacher in U. S. Lesson 4 provided an analogy of book pages in order to transform the knowledge of fossils and stratigraphy, saying, "So it's almost like looking back in a book, where the pages at the bottom contain fossils that are older than the pages on the top." Also, as shown in the following segment, the teacher made use of a student's experience as an analogical source when he explained the relationship between cooling and crystal size.

\section{1:05 T: But, anyway, how many people have ever made rock candy?}

21:16 SN: Me.

21:17 T: All right. The longer you let that string hang in the water, what about the size of the crystal? Did you make it that way?

21:28 SN: No, never,

An instance of the sequential connection of the 'retrieving - reformulating - elaborating' discourse modes was observed in Lesson 1 . In the beginning of this lesson, the teacher posed a few questions to review previously learned scientific concepts of air masses and fronts. But, when a student failed to complete his answer, the teacher started his reformulating discourse in which he introduced physical models of weather fronts made out of balloons with different colors. The following except shows a part of the two minute-long reformulating discourse.

06:24 T: Okay. Let me show you a real easy way to really kind of understand it. I have three balloons this time, and they are different color. Red is? $\cdots$

06:35 SS: Warm.

06:36 T: Warm air. Blue is?

06:37 Ss: Cold.

06:38 T: Cold, and yellow is?

06:39 SS: Warm.

06:40 T: Is cooler. Let's say cooler. All right. Let's look up here for a second. '. So where would the red balloon go? If this is the, what kind of front?

07:03 SS: Cold.

07:04 SN: Cold front.

07:05 T: Then where's the warm air going to be?

07:07 SS: Going behind it.

07:08 T: Behind it? This is the front of a warm air mass?

07:12 SN: Un, no. It's gonna be in front of it.

07:13 T: It's gonna be in front of it?

07:14 SN: Yeah.

07:15 T: Okay. Where's the cold air gonna be? ...

Meaningfully, the reformulating discourse above induced a question from a student who wanted more information on the movement of air masses, which resulted in elaborating discourse between the teacher and students. The reformulating discourse of these sorts is believed to provide an exemplary way of alternative representation of complicated knowledge, which students can also apply in their 
own learning to enhance their understanding of scientific knowledge. In this regard, the conclusion can be made that the reformulating discourse found in the U.S. science classrooms fulfilled the same pedagogical function as elaborating discourse. Furthermore, it can be reasoned properly that as in Japanese science lessons, the reformulated scientific knowledge became an important component of CSK in the U.S. classrooms.

\section{Discussion and Conclusion}

In this study, we have investigated ten $8^{\text {th }}$ grade science lessons of five Third TIMSS participating nations in order to understand how the teacher and students build classroomsituated scientific knowledge, namely CSK. The analysis of science classroom discourse revealed a range of discursive modes utilized in the classrooms. While teacher-initiated metadiscourse and retrieving discourse were commonly abundant in the science lessons, other discursive modes including exploring, building-on-theshared, negotiating, elaborating, and reformulating, were also identified. Students were engaged in such various discursive modes through the teacher's leading and guidance, and sometimes they played active roles in elaborating, debating, and negotiating discourse. Different discursive modes were often sequentially linked to develop CSK in the classrooms. It can therefore be concluded that knowledge-building processes in the science classrooms were dynamic ones in which the teacher and students socially and discursively interact in a flow of several interlocking discourse modes.

Beyond this general conclusion, the study identified three salient patterns of science classroom discourse: teacher-guided negotiation and the sequential connections of exploring (scientific phenomena) - building on the shared and retrieving - elaborating. Teacher-guided negotiation referred to the discursive practice in which the teacher challenged students discursively and guided them in such ways that they could reach more sophisticated understanding and be able to express their understanding in adequate uses of scientific language. The sequence of exploring - building on the shared meant that the class was first engaged in practical activities, such as science demonstrations, small group experiments, and discussion, and scientific knowledge was built on the basis of the results of these activities. The newly built knowledge often included more comprehensive scientific ideas and therefore afforded explanations of the explored phenomena. Although sometimes exploring discourse for eliciting student ideas took place prior to the exploring of scientific phenomena and sometimes elaborating discourse followed the building-on-the-shared mode, central was the pattern of 'exploring (scientific phenomena) - building (new knowledge) on the shared (exploration)'. In the retrieving - elaborating sequence, students first learned scientific knowledge from the teacher and were then provided with more information to expand and enhance the knowledge. The retrieving discourse was realized either in the teacher' s monologue or through the exchange of teacher question and student answer similar to the IRE pattern. The teacher again assumed the major role in the elaborating discourse in which concrete examples or materials were used for making abstract scientific ideas readily understandable to students. At times reformulating and exploring discourses complemented or replaced the elaborating discourse and served the same pedagogical function.

While these three discursive patterns were found salient, dominant ones varied among different lessons or different countries. That is, teacher-guided negotiation was commonly observed in Australia Lesson 5 and Dutch Lesson 1. The exploring - building on the shared sequence was found more often in Australian and Japanese science lessons, whereas the retrieving - elaborating connection was observed 
frequently in Czech and U.S. science classrooms. In addition, the students in Dutch Lesson 5 were observed to be more actively engaged in such discursive modes as elaborating, exploring, and debating. Although one of our research objectives was to identify differences in science classroom discourse among different countries, we hesitate to conclude that the differences we found actually reflected the cultural traits peculiar to the nations. Rather, we are open to alternative explanations. As an example, the differences in dominant discursive patterns might be attributed to the differences in class types. As described previously, Australian and Japanese lessons, where the exploring - building on the shared sequence were dominant, were organized in practical work such as teacher demonstrations and student experiments. In contrast, both Czech Lesson 2 and U.S. Lesson 5 operated as a teacher lecture, and the retrieving - elaborating sequence were abundant in these lessons. Also, Dutch Lesson 5 dealt with a social issue related to scientific knowledge and therefore included relatively various studentengaged discourse modes as compared with other classes. Hence, there is a possibility that the differences in classroom discourse were influenced by class types, rather than merely reflecting the culture of each nation.

However, we have also seen a common characteristic in the three salient discursive patterns, as well as other discursive modes and their connections described in the findings: the teacher plays key roles in almost all the discursive practices. This feature seems to exist beyond geographic and cultural boundaries of different countries and common across different types of classes. We found this suggesting the existence of unique epistemic cultures shared among science classrooms in different countries and want to discuss this alternative explanation in more detail throughout the last of this section.

One of the goals of education is to offer young learners access to disciplinary discourse when discourse is defined as a form "of language which are generated by the language practices of group of people with shared interest and purposes" (Mercer, 1995, p. 81). In the context of science education, learning science involves exercising the discourse of science, and therefore teachers of science make an effort to help students appropriate standard ways of talking science that are held privileged within scientific communities (Driver, 1989; Hogan et al., 2000; Mortimer \& Scott, 2003). In our current study, however, little evidence was found that students internalized scientific discourse and used it to solve problems meaningful to them. For example, the students were not observed building new knowledge on their own science experiences, and they did not participate in genuine negotiating discourse with their peers to resolve conflicts around scientific issues. Although the teachers explored student ideas frequently, they seldom led the learners in the sequence of exploring - debating - negotiating discourse. The scaffolding discourse mode which can demonstrate students' independent competence in doing and talking science only appeared once. All these discursive features are likely to be the case in scientists' professional activities, but they were deficient in the science classrooms observed in this study.

For this lack of discourse mirroring scientists' practices, it can be proposed as an explanation that the knowledge process in the science classroom is inherently different from that of the community of professional scientists. KnorrCetina (1999) conceptualized the ways of knowledge production in scientific communities as epistemic cultures, which are defined as "those amalgams of arrangements and mechanism $\cdots$ which, in a given field, make up how we know what we know" (p. 1, italics in original). If her concept of epistemic cultures can apply to all cultural communities, it is reasonable to say that the science classroom has a unique epistemic culture which is common to different countries and distinguishable from 
those of other intellectual communities. The epistemic culture of science classrooms, if it exists and is understood properly, could explain more comprehensibly how CSK is built in such ways that were identified in this study. Also, understanding of the epistemic culture would provide practical implications, not the least of which would be science education reform based on real lives in science classrooms.

The findings of this study are not sufficient enough to define the epistemic culture of science classrooms. But, a useful insight can be obtained by pondering some of the findings. For example, the sequential connection of exploring - building on the shared modes implies that when practical work of science is adapted into school classrooms, it is likely implemented in a manner of guided inquiry. Guided inquiry is characterized by problems and processes being structured in some degree and by students being led to particular answers known to the teacher, rather than being told the answers directly from the teacher. Although experimental materials and equipment are prepared by the teacher, students are allowed to work in small groups to generate their own data and formulate their own explanations (Colburn, 2000; Furtak, 2006; Herron, 1971). To engage students in guided inquiry, teachers of science take on various pedagogical roles, including identifying student ideas resonant with scientific ones and promoting their development, strengthening the background knowledge of learners for use in solving problems, and assisting students in building up scientific interpretations of data (Acher et al., 2009; Crawford, 2000; Oh, 2010). These teacher roles as well as the structural characteristics of guided inquiry were also identified in some lessons examined in this study. That is, it was the teacher who mediated student investigations of scientific phenomena through exploring discourse. He/she presented scientific knowledge on the basis of the experiences shared with students, so that common scientific understanding could be reached in the class. Besides, if misconceptions or flaws were found in student reasoning, the teacher invited the students in talk and led them discursively to negotiate more adequate knowledge of science. The teacher also provided elaborations to help students enhance their understanding, and his/her reformulated representations of scientific ideas became important ingredients of CSK as versioned knowledge of expert scientific knowledge.

The importance of the teacher's discursive role has already been recognized in previous literature of science education. For example, Millar (2004) contended that "learning science at the school level is not the very discovery or construction of ideas that are new and unknown" (p. 7). Rather, students are expected to find out knowledge established by the scientific community, which is not possible "without being told" by the teacher (Millar, 1998, p. 19). Hofstein and Lunetta (2004) also emphasized the role of the teacher in classroom discourse when they suggested that laboratory work is not sufficient for students to achieve conceptual understanding of the scientific community. These notions are congruent with some of the epistemological understandings of Korean teachers who believe that school labs are different from scientists' work (Lee et al., 2011). The teacher-dominant feature of science classroom discourse is also consistent with that of mathematics classrooms in TIMSS participating Asian countries (Leung \& Park, 2005).

Thus, the fact that a great portion of science classroom discourse was devoted to the teacher suggests that CSK is a product of the teacher' $\mathrm{s}$ guidance and support for students to develop their understanding in alignment with canonical knowledge of science. Teacher-guided negotiation and the sequences of exploring - building on the shared and retrieving - elaborating, among many discursive patterns identified in this study, served as important mechanisms for the teacher to fulfill this pedagogical role. Based upon these, 
it can be proposed that the epistemic culture of science classrooms consists fundamentally of attempts at sharing knowledge which is yet unknown to others or undeveloped within participants. That is, in school science classrooms, sophisticated knowledge and understanding of science which were possessed solely by the teacher is shared with students as a result of the social and discursive interaction between the teacher and students.

We present our conclusions concerning the existence of epistemic cultures in the science classroom as tentative and do not exclude the possibility of different argumentations. A limitation of the study is also acknowledged because in our study, only two classes of each country were analyzed. Therefore, the findings of this study have both similarities and differences as compared with those of other studies with the same data source (e.g., Roth et al., 2006; Roth \& Garnier, 2006/2007). For example, Roth and Garnier (2006/2007) concluded that Australian and Japanese science lessons were characterized by the evidence-based development of scientific concepts. This is similar to our finding that the exploring building on the shared sequence were dominant in the two countries. However, we viewed this discursive sequence as implying key roles of the teacher's discourse and found the same nuance in Czech and U.S. science classrooms, which in turn became a basis for us to suggest the epistemic culture of science classrooms. Considering possible differences in research findings and interpretations, we believe that careful and thorough investigations should be carried out to reveal epistemic cultures of science classrooms as well as to examine how strongly the discourse modes and their connections are influenced by cultural and contextual factors. The results from these subsequently proposed examinations are crucial to understand why school science classrooms are deficient in some significant features of scientific discourse and to find, if any, cultural/contextual differences which are reflected in science classroom practices and discourse.

\section{References}

Acher, A., Arca, M., \& Sanmarti, N. (2007). Modeling as a teaching learning process for understanding materials: A case study in primary education. Science Education, 91, 398418.

Aldridge, J., \& Fraser, B. (2000). A crosscultural study of classroom learning environments in Australia and Taiwan. Learning Environments Research, 3, 101-134.

Aldridge, J. M., Fraser, B. J., Taylor, P. C., \& Chen, C. - C. (2000). Constructivist learning environments in a cross-national study in Taiwan and Australia. International Journal of Science Education, 22(1), 37-55.

Barab, S. A., \& Duffy, T. M. (2000). From practice fields to communities of practice. In $\mathrm{D}$. H. Jonassen \& S. M. Land (Eds.), Theoretical foundations of learning environments (pp. 2556). Mahwah, NJ: Lawrence Erlbaum Associates.

Braaten, M., \& Windschitl, M. (2011). Working toward a stronger conceptualization of scientific explanation for science education. Science Education, 95, 639-669.

Brown, J. S., Collins, A., \& Duguid, P. (1989). Situated cognition and the culture of learning. Educational Researcher, 18(1), 32-42.

Campbell, T., Oh, P. S., Shin, M.-K., \& Zhang, D. (2010). Classroom instructions observed from the perspectives of current reform in science education: Comparisons between Korean and U.S. classrooms. Eurasia Journal of Mathematics, Science \& Technology Education, 6(3), 151-162.

Cazden, C. B. (1988). Classroom discourse: The language of teaching and learning. Portmouth, NH: Heinemann.

Colburn, A. (2000). An inquiry primer. Science Scope, 23(6), 42-44.

Collins, A., Brown, J. S., \& Newman, S. E. (1989). Cognitive apprenticeship: Teaching the 
crafts of reading, writing, and mathematics. In L. B. Resnick (Ed.), Knowing, learning, and instruction: Essays in honor of Robert Glaser (pp. 453-494). Hillside, NJ: Lawrence Erlbaum Associate.

Crawford, B. (2000). Embracing the essence of inquiry: New roles for science teachers. Journal of Research in Science Teaching, 37(9), 916-937.

Dow, W. (2006). The need to change pedagogies in science and technology subjects: A European perspective. International Journal of Technology and Design Education, 16(3), 307321.

Draper, S., \& Anderson, A. (1991). The significance of dialogue in learning and observing learning. Computers and Education, 17(1), 93-107.

Driver, R. (1989). The construction of scientific knowledge in school classroom. In $\mathrm{R}$. Millar (Ed.), Doing science: Image of science in science education (pp. 82-106). Philadelphia, PA: The Falmer Press.

Driver, R., Asoko, H., Leach, J., Mortimer, E., \& Scott, P. (1994). Constructing scientific knowledge in the classroom. Educational Researcher, 23(7), 5-12.

Edwards, D., \& Mercer, N. (1987). Common knowledge: The development of understanding in the classroom. New York: Methuen.

Furtak, E. M. (2006). The problem with answers: An exploration of guided scientific inquiry teaching. Science Education, 90, 453467.

Gee, J. P. (1999). An introduction to discourse analysis: Theory and method (2nd ed.). New York: Routledge.

Gee, J. P., Michaels, S., \& O’ Connor, M. C. (1992). Discourse analysis. In M. D. LeCompte, W. L. Millroy, \& J. Preissle (Eds.), The handbook of qualitative research in education (pp. 227291). San Diego, CA: Academic Press.

Greeno, J. G. (1995). Understanding concepts in activity. In C. A. Weaver, S. Mannes \& C. R. Fletcher (Eds.), Discourse comprehension: Essays in honor of Walter Kintsch (pp. 65-95). Hillsdale, NJ: Lawrence Erlbaum Associates.

Greeno, J. G., and the Middle School Mathematics Through Applications Project Group (1998). The situativity of knowing, learning, and research. American Psychologist, 53(1), 5-26.

Hennessy, S. (1993). Situated cognition and cognitive apprenticeship: Implications for classroom learning. Studies in Science Education, 22, 1-41.

Herron, M. D. (1971). The nature of scientific enquiry. School Review, 79(2), 171-212.

Hofstein, A., \& Lunetta, V. N. (2004). The laboratory in science education: Foundations for the twenty-first century. Science Education, 88, 28-54.

Hogan, K., \& Pressley, M. (Ed.) (1997). Scaffolding student learning: Instructional approaches and issues. Cambridge, MA: Brookline Books.

Hogan, K., Nastasi, B. K., \& Pressley, M. (2000). Discourse patterns and collaborative scientific reasoning in peer and teacher-guided discussions. Cognition and Instruction, 17(4), 379-432.

Johnson, C. (2007). Technical, political and cultural barriers to science education reform. International Journal of Leadership in Education, 10(2), 171-190.

Kelly, G. J., \& Crawford, T. (1997). An ethnographic investigation of the discourse processes of school science. Science Education, 81(5), 533-559.

Knorr Cetina, K. (1999). Epistemic culture: How sciences make knowledge. Cambridge, MA: Harvard University Press.

Kumpulainen, K., \& Wray, D. (2002). Classroom interaction and social learning: From theory to practice. London, UK: Routledge Falmer.

Lave, J., \& Wenger, E. (1991). Situated learning: Legitimate peripheral participation. Cambridge, UK: Cambridge University Press.

Leach, J., \& Scott, P. (2003). Individual and 
sociocultural perspectives on learning in science education. Science \& Education, 12(1), 91-113.

Lee, S.K., Lee, G.-H., \& Shin, M.-K. (2011). Exploring elementary teachers' epistemological understandings of school science lab practices. The Journal of Korean Teacher Education, 28(2), 21-49.

Lemke, J. L. (1990). Talking science: Language, learning, and values. Norwood, NJ: Ablex.

Leung, F. K. S., \& Park, K. (2005). Is mathematics teaching in east Asia conducive to creativity development? Results from TIMSS 1999 video study and the learners' perspective study. Journal of the Korean Society of Mathematical Education Series D: Research in Mathematical Education, 9(3), 203-231.

Mehan, H. (1979). Learning lessons: Social organization in the classroom. Cambridge, MA: Harvard University Press.

Mercer, N. (1995). The guided construction of knowledge: Talk amongst teachers and learners. Clevedon, UK: Multilingual Matters.

Mercer, N. (2000). Words and minds: How we use language to think together. London, UK: Routledge.

Mercer, N. (2008). The seeds of time: Why classroom dialogue needs a temporal analysis. The Journal of the Learning Sciences, 17, 33-59.

Michaels, S., Shouse, A., \& Schweingruber, H. A. (2008). Taking science to school: Learning and teaching science in grade $\mathrm{K}-8$. Washington, DC: National Academy Press.

Millar, R. (2004). The role of practical work in the teaching and learning of science. Paper prepared for the Committee: High School Laboratories. Washington, DC: National Academy of Sciences.

Millar, R. (1998). Rhetoric and reality: What practical work in science education is really for. In J. Wellington (Ed.), Practical work in school science: Which way now? (pp. 16-31) London: Routledge.

Mortimer, E. F., \& Machado, A. H. (2000). Anomalies and conflicts in classroom discourse.
Science Education, 84, 429-444.

Mortimer, E. F., \& Scott, P. H. (2003). Meaning making in secondary science classrooms. Maidenhead, UK: Open University Press.

Nassaji, H., \& Wells, G. (2000). What's the use of 'triadic dialogue'? An investigation of teacher-student interaction. Applied Linguistics, 21(3), 376-406.

National Research Council (1996). National Science Education Standards. Washington, DC: National Academy Press.

National Research Council (2011). A framework for $\mathrm{K}-12$ science education: Practices, crosscutting concepts, and core ideas. Committee on a Conceptual Framework for New K-12 Science Education Standards. Board on Science Education, Division of Behavioral and Social Sciences and Education. Washington, DC: The National Academies Press.

Nuthall, G. A. (1999). The processes involved in knowledge acquisition in the classroom. International Journal of Educational Research, 31, 189-212.

Ogborn, J., Kress, G., Martins, I., \& McGillicuddy, K. (1996). Explaining science in the classroom. Buckingham, UK: Open University Press.

Oh, P. S. (2005). Discursive roles of the teachers during class sessions for students presenting their science investigations. International Journal of Science Education, 27(15), 1825-1851.

Oh, P. S. (2010). How can teachers help students formulate scientific hypotheses? Some strategies found in abductive inquiry activities of earth science. International Journal of Science Education, 32(4), 541-560.

Oliveira, A. W., \& Sadler, T. D. (2008). Interactive patterns and conceptual convergence during student collaborations in science. Journal of Research in Science Teaching, 45(5), 634-658.

Osborne, J. F., \& Patterson, A. (2011). Scientific argument and explanation: A necessary distinction? Science Education, 95, 
627-638.

Piburn, M., Sawada, D., Falconer, K., Turley, J., Benford, R., \& Bloom, I. (2000). Reformed Teaching Observation Protocol (RTOP). ACEPT IN-003.

Richmond, G., \& Striley, J. (1996). Making meaning in classrooms: Social processes in small-group discourse and scientific knowledge building. Journal of Research in Science Teaching, 33(8), 839-858.

Roth, W.-M. (2005). Talking science: Language and learning in science classrooms. Lanham, MD: Rowman \& Littlefield.

Roth, K. J., Druker, S. L., Garnier, H. E., Lemmens, M., Chen, C., Kawanaka, T., Rasmussen, D., Trubacova, S., Warvi, D., Okamoto, Y., Gonzales, P., Stigler, J., \& Gallimore, R. (2006). Teaching science in five countries: Results from the TIMSS 1999 video study. Washington, DC: National Center for Education Statistics.

Roth, K. J., \& Garnier, H. (December 2006/January 2007). What science teaching looks like: An international perspective. Science in Spotlight, 64(4), 16-23.

Scardamalia, M., \& Bereiter, C. (2006). Knowledge building: Theory, pedagogy, and technology. In K. Sawyer (Ed.), Cambridge handbook of the learning sciences (pp. 97-118). New York: Cambridge University Press.

Scott, P., Mortimer, E. F., \& Aguiar, O. G. (2006). The tension between authoritative and dialogic discourse: A fundamental characteristic of meaning making interactions in high school science lessons. Science Education, 90, 605-631.

Tobin, K., Davis, N., Shaw, K., \& Jakubowski, E. (1991). Enhancing science and mathematics teaching. Journal of Science Teacher Education, 2(4), 85-89.

Vygotsky, L. S. (1978). Mind in society: The development of higher psychological processes. Cambridge, MA: Harvard University Press.

Vygotsky., L. S. (1981). The genesis of higher mental functions. In J. V. Wretch (Ed. and Trans.), The concept of activity in soviet psychology (pp. 144-188). Armonk, NY: M. E. Sharpe.

Vygotsky, L. S. (1987). Thinking and speech. In R. W. Rieber \& A. S. Carton (Eds.), The collected works of L. S. Vygotsky volume 1: Problmes of general psychology (pp. 37-285, translated by N. Minick). New York: Plenum.

Wells, G. (1993). Reevaluating the IRF sequence: A proposal for the articulation of theories of activity and discourse for the analysis of teaching and learning in the classroom. Linguistics and Education, 5, 1-37.

Wells, G. (1999). Dialogic inquiry: Toward a sociocultural practice and theory of education. Cambridge, UK: Cambridge University Press.

Wertsch, J. V. (1991). Voices of the mind: A sociocultural approach to mediated action. Cambridge, MA: Harvard University Press.

Westgate, D., \& Hughes, M. (1997). Identifying 'quality' in classroom talk: An enduring research task. Language and Education, 11(2), 125-139. 